\title{
Attention-memory training yields behavioral and academic improvements in children diagnosed with attention-deficit hyperactivity disorder comorbid with a learning disorder
}

\author{
This article was published in the following Dove Press journal: \\ Neuropsychiatric Disease and Treatment \\ 6 July 2017 \\ Number of times this article has been viewed
}

\author{
Antonio Carlos Farias ${ }^{1-4}$ \\ Mara L Cordeiro 1,2,5 \\ Erico PG Felden ${ }^{6}$ \\ Tiago S Bara ${ }^{1,2}$ \\ Cássia R Benko ${ }^{1,2}$ \\ Daniele Coutinho ${ }^{1,2}$ \\ Leandra F Martins ${ }^{2}$ \\ Rosilda TC Ferreira ${ }^{1,2}$ \\ James T McCracken ${ }^{5}$ \\ 'Faculdades Pequeno Príncipe, \\ ${ }^{2}$ Neurosciences Core, Pelé Pequeno \\ Príncipe Research Institute, Curitiba, \\ ${ }^{3}$ Department of Neuropediatrics, \\ Children's Hospital, Pequeno Príncipe, \\ ${ }^{4}$ School of Medicine, University \\ Positivo, Curitiba, Brazil; ${ }^{5}$ Department \\ of Psychiatry and Biobehavioral \\ Sciences, David Geffen School \\ of Medicine, Semel Institute for \\ Neuroscience and Human Behavior, \\ University of California, Los Angeles, \\ CA, US; ${ }^{6}$ Center for Health Science \\ Research, Santa Catarina State \\ University, Florianópolis, Brazil
}

Correspondence: Mara L Cordeiro Pelé Pequeno Príncipe Research Institute, 1632 Avenida Silva Jardim, Curitiba, PR 80250-I20, Brazil

Tel +554133101035

Fax +55 4l 3322 |446

Email mcordeiro@mednet.ucla.edu

\begin{abstract}
Background: Recent studies have suggested that children with attention-deficit hyperactivity disorder (ADHD) may benefit from computerized cognitive training. Therapy implementation is especially complicated when ADHD is associated with learning disorders (LDs). This study tested the efficacy of a computer-based cognitive training program, namely, computerized cognitive training (CCT), in children with ADHD comorbid with an LD (ADHD-LD), with or without psychostimulant medication.
\end{abstract}

Materials and methods: After diagnostic evaluations, 27 children with ADHD-LD ( 8 unmedicated and 19 medicated) participated in CCT, which is intended to improve attention, memory, reasoning, visual processing, and executive functioning. The participants completed 241 -hour sessions over 3 months. Neuropsychometric and standardized academic test results before and after training were compared to assess treatment efficacy. Shapiro-Wilk normality tests were applied, and subsequent Wilcoxon tests were used to identify significant differences in preversus post-training performance.

Results: After CAT, children diagnosed with ADHD-LD showed 1) improvements in trained skills, measured directly within the software and indirectly by external psychometric tests; 2) improvements in attention, memory, and some executive functioning; 3) improvements in academic performance, particularly in mathematics; and 4) reductions in maladaptive behavioral features. Conclusion: The present findings suggest that cognitive training programs should be explored further as potential adjunctive therapies to improve outcomes in children with ADHD-LD.

Keywords: attention-deficit hyperactivity disorder, attention training, computerized assessments, executive functioning

\section{Introduction}

Attention-deficit hyperactivity disorder (ADHD) is a common childhood-onset neurobehavioral disorder that affects $5 \%-7 \%$ of school-age children worldwide, independently of socioeconomic status. ${ }^{1-4}$ Therefore, in a classroom of 40 students, 3 children on average may have ADHD. The core symptoms of ADHD (eg, attentional deficit, impulsivity, and high motor-activity level) can hinder academic achievement and reduce the quality of life. ${ }^{5}$ Studies suggest that one in three children with ADHD may also have learning disorders (LDs). ${ }^{6}$ This comorbidity augments the cognitive problems and risk of academic failure and occupational and social outcomes in adulthood. ${ }^{7}$ Well-accepted therapeutic interventions for children with ADHD include pharmacological and/or psychosocial treatments. ${ }^{8}$ The American Academy of Child 
and Adolescent Psychiatry recommends that ADHD be treated with evidence-based stimulant medications and behavioral interventions. ${ }^{9}$ However, pharmacological treatment frequently does not ameliorate cognitive difficulties or auxiliary behavioral problems in children with ADHD, ${ }^{10}$ nor is it effective for children with ADHD comorbid with LD (ADHD-LD). However, to the extent that the child's maturity allows, families and educators can employ psychosocial approaches to help improve behavior. For example, cognitive behavioral therapy may reinforce adaptive behaviors and reduce disruptive behaviors. Educational interventions and speech therapy may also be necessary if there are specific deficits in verbal or symbolic language skills. Although behavioral interventions have been reported to have some positive effects in children with ADHD (eg, cognitive behavioral therapy), the effects thus far have been small, with very limited averaged effects on academic functioning. ${ }^{11-13}$

Untreated ADHD can be associated with unfavorable corollaries, such as truancy, low educational attainment, unemployment, accidents resulting in disability or premature death, and the development of neuropsychiatric comorbidities, such as conduct disorder, antisocial personality disorder, and substance abuse disorder. ${ }^{14}$ Consequently, researchers have been searching for alternative and/or complementary methods for ADHD management. One such approach involves computer-based cognitive games designed to improve attention and memory skills ${ }^{15,16}$ through learningdependent brain plasticity. ${ }^{17}$ ADHD-associated challenges that can be refractory to medication and might be improved through computer-based cognitive games include remaining difficulties with attention, memory, operational abilities, and executive organization, as well as comorbid LDs and maladaptive motivation and reward drives.

Computerized cognitive training (CCT; component of Captain's Log MindPower Builder; BrainTrain, North Chesterfield, VA, USA) has yielded some success in research settings. A prior study conducted by the Center for the Study of Special Populations demonstrated the efficacy of the Captain's Log CCT system in children diagnosed with ADHD ( $n=71)$ with respect to their ability to focus and sustain attention, encode and retrieve visual and auditory information, and conduct mental processing. ${ }^{18}$ Additionally, Rabiner et al found that 6 of 10 children with six or more ADHD symptoms were asymptomatic after completing 6 months of Captain's Log training. ${ }^{19}$ Likewise, adults with mild traumatic brain injury or ADHD that trained with CCT showed significant improvement in their attentional skills. ${ }^{20}$ Furthermore, it has been used successfully to rehabilitate cognition in Ugandan children diagnosed with cerebral malaria, ${ }^{21}$ and more recently, CCT has been used to improve working memory (WM) and attention skills in childhood cancer survivors. ${ }^{22}$

Relatively few studies on computer-based executive functions (EFs) and cognitive attention training have been published. To our knowledge, there have not been any studies addressing such training in children with ADHD in Brazil. Therefore, in this study, we tested whether CT with CCT would have beneficial effects on cognition in children diagnosed with ADHD-LD using or not using psychostimulants. We measured the effects of CCT through scores provided by the software and with psychometric instruments, which were incorporated to gauge training effects on the cardinal symptoms of ADHD, EFs, and other behavioral dimensions, such as anxiety and mood, which are known to compromise academic performance. To probe for the transfer of benefits to real-world situations, assessments of academic performance (ie, math, writing, and reading) and interpersonal functioning were also conducted.

\section{Materials and methods Participants}

Families whose children (boys or girls) had been diagnosed with ADHD-LD ${ }^{23}$ at our research institute were contacted by a social worker and invited to participate in the study. The children fitting our inclusion criteria were invited to participate in a CCT intervention study. The cohort was limited to children who were 8-12 years of age in the beginning of the study to decrease potential variables. The Ethics Committee on Human Research at the Little Prince Children's Hospital/Hospital Cesar Pernetta, Curitiba, Brazil (protocol CEP1057) approved the study including all aspects of the research protocol.

Initially, the parents responded to four simple questions about their child's academic performance, current behavior at home and school, and adherence to treatment. Of 150 families who were contacted, 30 fitted the inclusion criteria, and were invited to participate in the study. Of these, 3 did not complete the study, and the remaining 27 did.

Inclusion criteria included meeting the ADHD diagnosis criteria after being subjected to the multidisciplinary team assessment protocol of the research institute's Neurosciences Core; full-scale IQ $>80$ based on the present performance as per Wechsler Intelligence Scale for Children, third edition (WISC-III); ${ }^{24} \geq 2$ years of literacy education; and written informed consent agreement by the parents 
allowing their children to participate was received for this study. Exclusion criteria included visual and/or hearing impairment; a history of epilepsy; endocrine dysfunction; cardiopulmonary, systemic, or other chronic disease; and participation in other types of cognitive therapy in the 12 months preceding the study. Two groups were configured: group A, participants medicated with immediaterelease methylphenidate $20 \mathrm{mg}$ /day $(\mathrm{n}=19)$; and group $\mathrm{B}$, unmedicated participants $(\mathrm{n}=8)$.

\section{Measures}

\section{Computerized Diagnostic Interview Schedule for Children}

Assessment of psychiatric disorders was performed with the Computerized Diagnostic Interview Schedule for Children. ${ }^{25}$ This is a highly structured interview based on the Diagnostic and Statistical Manual of Mental Disorders (DSM-IV-TR) criteria. ${ }^{26}$ Interviews were conducted by well-trained clinical psychologists and were administered to the children and a parent (typically the mother).

We also determined the level of impairment with a social worker-administered questionnaire with open questions probing the overall relationship of each child with his or her parents, teachers, siblings, and schoolmates. Each child's academic performance was estimated based on Brazilian school achievement test [Teste do Desempenho Escolar (TDE)] results, grades, and detention frequency. General level of psychosocial functioning was measured with the Children's Global Assessment Scale. ${ }^{27}$ We held meetings to discuss the results of the aforementioned assessments and any issues that may have been contributing to each child's behavioral and/or learning difficulties. Final diagnoses were affirmed by consensus.

\section{Wechsler Intelligence Scale for Children}

Cognitive ability was assessed with a version of the WISCIII $^{24}$ that had been translated into Portuguese and adapted for the Brazilian population. With the exception of the Mazes subtest, all of the IQ scale/index, verbal, and performance subtests in the Portuguese WISC-III had been culturally adapted and validated previously in a sample of 801 Brazilian subjects aged $6-16$ years. ${ }^{28}$

\section{d2 test}

Visual sustained attention was assessed with the $\mathrm{d} 2$ test, which consists of 14 lines with 47 symbols on each line. ${ }^{29}$ The symbols are either the letter $\mathrm{d}$ or the letter $\mathrm{p}$ with one, three, or four small dashes above or below the letter. The participant is asked to go through the lines and cross out all $\mathrm{d}$ symbols with one or two dashes above or below them. The test is reported with a d2 total score, a d2 type 1 error (error of omission) score, and a d 2 type 2 error (error of commission) score. Here we report total results, brut results, and liquid results (ie, brut results - total results).

\section{Wisconsin Card Sorting Test (WCST)}

The $\mathrm{WCST}^{30}$ is designed to measure EFs, including planning, flexibility of thought, WM, monitoring, and inhibition of perseveration. It consists of 4 prompt letters and 128 reply letters, which represent figures of various forms (crosses, circles, triangles, or stars), colors (red, blue, yellow, or green), and numbers (two, three, or four). The four letter cards (ie, stimuli) are arranged in front of the subject; the test administrator tells the subject only to remove a card from the deck and associate it with one of the four letter cards by positioning it below the card of choice. The administrator tells the subject whether the association is correct or incorrect, with no further explanation, before proceeding to the next card sorting trial. The "correct" association is based on the color (C) for the first 10 trials, the form/shape (F) for the next 10 trials, and the number $(\mathrm{N})$ for the next 10 trials; and this sequence is repeated, producing a CFNCFN pattern over a total of 128 trials. If the subject makes an association that is not based on $\mathrm{C}, \mathrm{F}$, or $\mathrm{N}$, the association is classified as "other". The following variables were recorded: total number of errors, percentage of errors, perseverative responses, percentage of perseverative responses, perseverative errors, percentage of perseverative errors, nonperseverative errors, percentage of nonperseverative errors, and percentage of conceptual-level responses.

\section{Rey-Osterrieth Complex Figure (ROCF) test}

The ROCF test ${ }^{31,32}$ was used to access visuospatial processing and nonverbal memory. It is also thought to reflect some EFs, such as organization and planning. The subject is shown a complex geometric figure and then asked to draw the figure from memory after a 3-minute delay.

\section{WM index}

For the purposes of the proposed study, we used digit-span sequencing forward and backward of the subtests of the WISCIII as one of the measures of WM index.

\section{Computerized cognitive training}

CCT is a component of the Captain's Log software system, which is designed for use with children aged $>6$ years old 
and adults. It is composed of a group of 50 training programs that provide a variety of $36 \mathrm{CT}$ exercises. One-hour sessions were conducted twice weekly over a period of 3 months (total of 24 sessions) at our research Institute. For the current study, exercises were chosen as follows: 1) attention-skills module - scanning reaction/inhibition, stimulus reaction/ time, and stimulus reaction/fields; 2) conceptual/memory skills module - conceptual, logical, size discrimination, and symbol display match; 3) visual motor skills module - visual categorization, visuospatial memory, and visual time response; and 4) logic skills module - conceptual, matching, and sequential logic. Exercises included the following (skills trained in parentheses):

- Participant is presented with varied images and uses a mouse click to indicate as quickly as possible when the image color matches the edge of the screen (visual tracking, response inhibition, sustained attention, and visual processing)

- Participant clicks target images among distracter images (focused attention, selective attention, visual processing speed, visual perception, sustained attention, and response inhibition)

- Participant clicks random images that appear on the screen as quickly as possible (fine motor skills, sustained attention, visual processing speed, and visual screening)

- Participant finds components missing from presented sequences of letters, numbers, or images (processing speed, conceptual reasoning, WM, visual perception, and immediate memory)

- Participant clicks target images in a specified sequence (conceptual reasoning, visuospatial sequencing, selective attention, visual processing speed, and WM)

- Participant clicks objects presented within a grid of objects in order of size (trains fine motor skills, conceptual thinking, visuospatial classification, visuospatial sequencing, visual perception, and visual screening)

- Participant selects target images and places them in bins based on set of rules (conceptual reasoning, processing speed, visuospatial classification, sustained attention, and immediate memory)

- Participant finds pairs of objects in a grid, revealing objects one at a time, similar to the traditional game of memory (conceptual reasoning, WM, processing speed, and visual perception)

- Participant tracks doors as they open, clicking only when target object is revealed (visual tracking, conceptual thinking, visual perception, response inhibition, and visual processing speed)
- Participant observes target grid and clicks as quickly as possible when targets change visually (visual processing speed, visual tracking, visual perception, attentionfocused, sustained attention, and fine motor skills)

- Participant solves rules determining sequence of various objects (conceptual reasoning, sorting, sequencing, spatial vision, visual perception, and sustained attention)

- Participant judges whether presented images fit the given rule (sorting visual space, conceptual reasoning, visual perception, short-term memory, visual processing speed, selective attention)

- Participant demonstrates the understanding of rules dictating conceptual logic between numbers or letters presented (conceptual reasoning, visuospatial sequencing, attention, processing speed, visual screening).

At the end of each training session, the software informs each participant of his or her performance scores, times, and accuracy. Specifically, the participant is given scores for memory power, problem solving, power of concentration, visual processing, and power of self-discipline. The scores for these variables on the first and last training sessions were compared.

\section{Statistical analyses}

Mean values were calculated with standard deviations. Dataset normality was determined with the Shapiro-Wilk test. The Wilcoxon test was used to identify the differences between pre- and posttest performance (with medication use as an independent variable). A probability level of $P<0.05$ was considered significant. All statistical analyses were conducted with SPSS version 21.0.

\section{Results}

\section{Clinical and demographic characteristics}

The clinical and demographic characteristics of the two groups (medicated and unmedicated) are summarized in Table 1. The groups did not differ from each other with respect to age, overall intelligence, or socioeconomic status.

Table I Sample demographics

\begin{tabular}{lll}
\hline Demographics & Unmedicated $(\mathbf{n}=\mathbf{8})$ & Medicated $(\mathbf{n}=\mathbf{1 9})$ \\
\hline Mean age (SD), years & $\mathrm{II} . \mathrm{I}(\mathrm{I} .5)$ & $9.4(1.5)$ \\
Sex, male:female (n=27) & $4: 4$ & 14.5 \\
Mean IQ score (SD) & & \\
$\quad$ Total & $105.5(16)$ & $108.7(16.6)$ \\
$\quad$ Verbal & $98.3(20.5)$ & $109.0(18.8)$ \\
Execution & $110.8(17.2)$ & $108.2(14.4)$ \\
\hline
\end{tabular}

Abbreviation: SD, standard deviation. 
Table 2 Group comparisons of mean (SD) CCT accuracy scores

\begin{tabular}{|c|c|c|c|c|c|c|}
\hline \multirow[t]{2}{*}{ Variables } & \multicolumn{3}{|c|}{ Unmedicated $(n=8)$} & \multicolumn{3}{|c|}{ Medicated $(n=19)$} \\
\hline & $\overline{\text { Pre-CCT }}$ & Post-CCT & $P$-value & Pre-CCT & Post-CCT & $P$-value \\
\hline Memory power & $83.2(7.0)$ & $90.7(3.0)$ & $0.028^{*}$ & $84.1(4.0)$ & $90.5(4.7)$ & $0.01 I^{*}$ \\
\hline Problem solution & $88.5(4.4)$ & $93.6(2.6)$ & $0.018^{*}$ & $90.4(2.0)$ & $93.9(3.2)$ & $0.003 *$ \\
\hline Concentration power & $91.3(3.9)$ & $95.3(2.6)$ & $0.018^{*}$ & $93.1(1.8)$ & $95.5(2.5)$ & $0.004 *$ \\
\hline Visual processing & $90.3(4.5)$ & $94.4(2.4)$ & $0.018^{*}$ & $92.2(1.7)$ & $94.6(2.8)$ & $0.00 I^{*}$ \\
\hline Self-discipline & $91.4(3.4)$ & $94.7(2.0)$ & $0.018^{*}$ & $92.6(2.1)$ & $94.5(2.7)$ & $0.019 *$ \\
\hline Auditory processing & $92.1(5.0)$ & $95.3(2.8)$ & $0.018^{*}$ & $93.5(2.2)$ & $96.2(2.2)$ & $0.004 *$ \\
\hline
\end{tabular}

Note: $* P<0.05$.

Abbreviations: SD, standard deviation; CCT, computerized cognitive training.

Preintervention performance levels were similar between the two groups.

\section{CCT performance}

The overall performance results of the medicated and unmedicated ADHD-LD groups in CCT are summarized in Table 2. Both groups showed significant improvements in memory, problem solving, concentration, visual and auditory processing, and self-discipline exercise performance with training.

\section{Neuropsychological and behavioral assessments}

As shown in Table 3, CCT improved percentage memory performance in the ROCF test significantly in both the medicated and unmedicated groups, but improved only

Table 3 Efficacy of CCT in children with ADHD-LD

\begin{tabular}{|c|c|c|c|c|c|c|}
\hline \multirow[t]{2}{*}{ Assessment } & \multicolumn{3}{|c|}{ Unmedicated $(n=8)$} & \multicolumn{3}{|c|}{ Medicated $(n=19)$} \\
\hline & Pre-CCT & Post-CCT & $P$-value & Pre-CCT & Post-CCT & $P$-value \\
\hline \multicolumn{7}{|l|}{$\mathrm{d} 2$ test results $(\mathrm{SD})$} \\
\hline Raw score & $35.5(12.3)$ & $54.1(29.5)$ & $0.027 *$ & 46.I (29.3) & $58.7(33.7)$ & $0.004 *$ \\
\hline Net score & $39.3(21.1)$ & $58.4(31.6)$ & $0.027^{*}$ & $44.5(32)$ & $64.3(31.5)$ & $0.002 *$ \\
\hline Errors, \% & $57.5(28.7)$ & $54.2(32.9)$ & $0.14 \mid$ & $55.8(36)$ & $56.2(36.8)$ & 0.439 \\
\hline \multicolumn{7}{|l|}{ WCST errors (SD) } \\
\hline Perseverative & $43.8(17.6)$ & $53.1(20.1)$ & $0.028 *$ & $44.1(13.4)$ & $51.7(15.2)$ & $0.012^{*}$ \\
\hline Nonperseverative & $54.6(14.8)$ & $51.4(4.6)$ & 0.463 & $49(13.4)$ & $57(10.4)$ & 0.074 \\
\hline Total errors & $45.2(13.1)$ & $57.4(15)$ & $0.043 *$ & 44.1 (II.5) & $53.5(11.2)$ & $0.001^{*}$ \\
\hline \multicolumn{7}{|l|}{ ROCF test results (SD), \% } \\
\hline Copied & $36.8(14.4)$ & $46.4(23.9)$ & 0.577 & $31.8(24.5)$ & $45.5(28.7)$ & $0.005^{*}$ \\
\hline Memory & $26.8(11.6)$ & $62.1(23)$ & $0.018^{*}$ & $38.4(20.7)$ & $52.5(28.4)$ & $0.026^{*}$ \\
\hline \multicolumn{7}{|l|}{ Mean WM indices (SD) } \\
\hline Digit span backward & $4.6(2.7)$ & $3.7(1.3)$ & 0.458 & $4.2(2.5)$ & $4.7(2.1)$ & 0.17 \\
\hline Digit span forward & $6.1(1.8)$ & $7(\mathrm{I} .2)$ & 0.131 & $6.6(1.7)$ & $6.4(1.8)$ & 0.886 \\
\hline Arithmetic & $13.3(2.5)$ & $14(2)$ & 0.713 & $13.2(3.2)$ & $14.7(2.4)$ & $0.021 *$ \\
\hline Total, \% & $28.2(24.9)$ & $39.5(32.5)$ & $0.018^{*}$ & $44.4(32.7)$ & $63.5(30.6)$ & $0.00 I^{*}$ \\
\hline \multicolumn{7}{|l|}{ Mean CBCL scores (SD) } \\
\hline Attention problems & $64.3(10.2)$ & $61.4(12)$ & $0.027^{*}$ & $67.5(6.9)$ & $64.2(6.7)$ & $0.023^{*}$ \\
\hline Internalizing problems & $53.6(6.4)$ & $57.1(9.3)$ & 0.752 & $65.3(9.5)$ & $61(10)$ & $0.007^{*}$ \\
\hline Externalizing problems & $57.7(9.7)$ & $52.2(I 1.8)$ & 0.345 & $64.6(8)$ & $60(8.6)$ & $0.01 *$ \\
\hline Total problems & $59.2(9.3)$ & $57(10.2)$ & 0.462 & $67.5(5.6)$ & $62.4(7.6)$ & $0.009 *$ \\
\hline \multicolumn{7}{|l|}{ TDE scores (SD) } \\
\hline Total & $102.7(17.3)$ & III.8 (I4.5) & $0.043 *$ & $97.2(22.2)$ & $101.8(19.8)$ & $0.001 *$ \\
\hline Math & $17(5.5)$ & $18.4(6.8)$ & 0.458 & $15(8.8)$ & $15.3(9.1)$ & 0.482 \\
\hline Reading & $61.5(6.4)$ & $65.4(5.2)$ & 0.112 & $60.3(9.2)$ & $65.1(7.8)$ & $0.006 *$ \\
\hline Writing & $24.2(6.8)$ & $28.5(5.7)$ & 0.061 & $21.8(6.8)$ & $23.2(6.8)$ & $0.037^{*}$ \\
\hline
\end{tabular}

Note: $* P<0.05$.

Abbreviations: CCT, computerized cognitive training; ADHD, attention-deficit hyperactivity disorder; LD, learning disorder; SD, standard deviation; WCST, Wisconsin Card Sorting Test; ROCF, Rey-Osterrieth Complex Figure; WM, working memory; CBCL, Child Behavior Checklist; TDE, [Teste do Desempenho Escolar (Brazilian schoolachievement test)]. 
percentage copy performance in the medicated group. Both groups showed a significant improvement in both their brut and liquid results in the $\mathrm{d} 2$ test, with no improvement in the percentage of errors. Both groups had better performance on the WCST post-CCT versus pre-CCT in terms of the number of total errors and the number of perseverative errors. Nonperseverative errors were similar pre- versus post-CCT for both groups. Importantly, our Children's Global Assessment Scale data indicated that CCT had a positive impact on attentional problems in both the medicated and unmedicated groups, as well as a significant positive impact on internalizing, externalizing, and total problems in the medicated group (Table 3).

\section{Transfer effects}

TDE test results pre- and postintervention are presented by subject in Table 3. Both groups showed significantly improved overall TDE performance, with the effects being highly significant in the medicated group $(P<0.001)$. When subject subscores were examined independently, the medicated group showed post-CCT improvements in writing and reading, but not on the math scores. However, at school the children's grades showed similar improvements, with the most notable improvements being observed in math, with a 10 -point increase in overall grade.

\section{Discussion}

The main objective of this research was to test whether CCT alone or in association with psychostimulant medication could produce cognitive, attentional, behavioral, and academic benefits for children diagnosed with ADHD-LD. Both the medicated and unmedicated groups exhibited significantly improved performance on all CCT-trained skills after the intervention. First-line pharmacological medications used to treat ADHD can also be considered "cognitive enhancers". ${ }^{33}$ Although the precise neurobiological mechanism of action of methylphenidate, which is currently used to treat $\mathrm{ADHD}$, is not entirely known, it has some action by increasing dopamine and norepinephrine by blocking reuptake, and this action in turn affects neurocognitive processes, such as impulse control and attention span. ${ }^{34}$ These effects will ultimately alter synaptic plasticity. However, CCT has also been shown to alter synaptic plasticity. With a small group of participants, here we have shown that CCT had a positive effect on both medicated and unmedicated ADHD children. Prior studies ${ }^{19,20}$ have also shown the positive effects of Captain's Log software, including CCT, in individuals diagnosed with ADHD. Most importantly, we observed significant transfer effects of the CCT, and we also found that both medicated and unmedicated children can benefit from CCT. Most neuropsychological tests showed significant post-CCT improvements in both groups (eg, d2 test, WCST [perseverative and total errors], and ROCF test [immediate recall]). On the overall WM test, both groups showed better results after training.

Regarding transfer effects, we observed that both TDE scores and academic performance (actual school grades) were improved post-training, with the improvement being particularly marked in children that were medicated. Our findings are consistent with those of Holmes et al, who found that medicated ADHD children had better mathematical performance but not better reading comprehension after WM training, ${ }^{33}$ whereas Dahlin et al found improved reading comprehension with an EF-focused WM training program. ${ }^{34}$ Studies have suggested that academic difficulties in children with ADHD-LD are related more to inattention than hyperactivity. ${ }^{35-37}$ If so, then children with ADHD-LD should perform better in school when their attentional problems are alleviated.

Although medication moderates some ADHD symptoms, ${ }^{38}$ it does not appear to improve WM in children with ADHD with or without LD. ${ }^{39,40}$ Our overall WM (total percentage) results were consistent with previous research demonstrating the efficacy of WM training in adolescents with ADHD-LD, with particularly marked improvement having been observed previously for children who had been unresponsive to typical interventions. ${ }^{41}$

Although we did not directly measure any possible synaptic plasticity, studies have shown that some CCT may alter synaptic connectivity. For example, repetitive auditory stimulation over the second week of life has been shown to induce plasticity in the auditory cortex and to modify adulthood hearing perception in animals. ${ }^{42}$ Moreover, computerized training improved trained cognitive skills in human patients with schizophrenia ${ }^{43}$ and multiple sclerosis ${ }^{44}$ and induced changes in brain activation patterns, as evidenced by functional neuroimaging. Improved WM in individuals affected by ADHD with computerized training has also been shown to correlate with changes in the pattern of activation of neural networks in the frontal and parietal cortices, suggesting that the behavioral improvements may reflect plasticity in WM circuits. ${ }^{45}$ It would certainly be of interest to pursue longitudinal studies to test the limits of these correlations and when skill plateaus emerge. Furthermore, some studies have already documented modifications in brain function following computer-based training targeting attentional 
skills. For example, 5-year-olds subjected to such training showed faster, more effective activation of their executiveattention network than children who were not trained. ${ }^{46}$ In another study of healthy adults who completed 90 WM exercises over a period of 20-30 days, functional magnetic resonance imaging showed greater activation in the prefrontal and parietal areas after training. ${ }^{47}$ More recently, WM training in healthy subjects was associated with activation changes in the frontal and parietal cortices. ${ }^{45}$

This work has some limitations. 1) Because our sample size was small and nonrandomized, our findings should be replicated in a larger randomized study. Recent studies using another intervention program, Cogmed, in a randomized controlled trial, showed that ADHD-LD adolescents showed greater improvements in a subset of WM tests, but they did not observe any transfer effects. ${ }^{48}$ 2) Our study lacked untrained and healthy comparison groups. That being said, we do not expect benefits of CCT should be limited to children with ADHD and LD. In a recent study, healthy adults ( $n=44)$ subjected to 6 weeks of CCT showed enhanced cognitive performance and better productivity at their jobs, ${ }^{47}$ suggesting the program may benefit cognitive functioning independently of the presence of impairments. 3) We did not collect neurophysiological or neuroimaging data in this study. Prior studies as mentioned, reported changes in brain circuitry, consequence of WM training. ${ }^{46-50}$

In conclusion, the present findings suggest that CCT may have cognitive, attentional, and academic benefits for children with ADHD-LD. CC, WM, and attentional programs should be explored further as complementary therapies along with medication.

\section{Acknowledgments}

Funding for the research was provided by the Secretaria Ciência e Tecnologia e Ensino Superior do Estado do Paraná (SETI, CV012/10), Brazil, to MLC. The authors are grateful to the families and children who participated in the study.

\section{Author contributions}

MLC and JTM were coprincipal investigators. MLC, JTM and ACF conceptualized and designed the study protocol. CRB, DC, TSB, LFM and RTCF performed data acquisition. MLC and ACF analyzed, interpreted the findings and wrote the manuscript. EPGF performed all the statistical analysis and helped with critical interpretation of the data. MLC performed a critical revision of the manuscript for important intellectual content and was responsible for submitting the final approved manuscript. The study was part of a doctoral thesis for ACF. All authors helped with revising the paper, and agree to be accounted for all aspects of the work.

\section{Disclosure}

The authors report no conflicts of interest in this work.

\section{References}

1. Swanson J, Castellanos FX, Murias M, LaHoste G, Kennedy J. Cognitive neuroscience of attention deficit hyperactivity disorder and hyperkinetic disorder. Curr Opin Neurobiol. 1998;8(2):263-271.

2. McCracken J. Textbook of Pediatric Neuropsychiatry. Coffey E, Brumback R, editors. American Psychiatric Association Press; In press 1998.

3. Barkley RA, Fischer M, Smallish L, Fletcher K. Young adult outcome of hyperactive children: adaptive functioning in major life activities. J Am Acad Child Adolesc Psychiatry. 2006;45(2):192-202.

4. Margari L, Buttiglione M, Craig F, et al. Neuropsychopathological comorbidities in learning disorders. BMC Neurol. 2013;13:198.

5. Swanson J, Arnold LE, Kraemer H, et al. Evidence, interpretation, and qualification from multiple reports of long-term outcomes in the Multimodal Treatment Study of children with ADHD (MTA) - part II: supporting details. J Atten Disord. 2008;12(1):15-43.

6. Dulcan MK, Benson RS. Summary of the practice parameters for the assessment and treatment of children, adolescents, and adults with ADHD. J Am Acad Child Adolesc Psychiatry. 1997;36(9):1311-1317.

7. Gualtieri CT, Johnson LG. Medications do not necessarily normalize cognition in ADHD patients. J Atten Disord. 2008;11(4):459-469.

8. Chambless DL, Ollendick TH. Empirically supported psychological interventions: controversies and evidence. Annu Rev Psychol. 2001; 52:685-716.

9. Fabiano GA, Pelham WE Jr, Coles EK, Gnagy EM, Chronis-Tuscano A, O'Connor BC. A meta-analysis of behavioral treatments for attentiondeficit/hyperactivity disorder. Clin Psychol Rev. 2009;29(2):129-140.

10. Pelham WE Jr, Fabiano GA. Evidence-based psychosocial treatments for attention-deficit/hyperactivity disorder. J Clin Child Adolesc Psychol. 2008;37(1):184-214.

11. Perwien A, Hall J, Swensen A, Swindle R. Stimulant treatment patterns and compliance in children and adults with newly treated attention-deficit hyperactivity disorder. J Manag Care Pharm. 2004;10(2):122-129.

12. Barkley RA, Fischer M. Predicting impairment in major life activities and occupational functioning in hyperactive children as adults: self-reported executive function (EF) deficits versus EF tests. Dev Neuropsychol. 2011;36(2):137-161.

13. Schachar RJ, Tannock R, Cunningham C, Corkum PV. Behavioral, situational, and temporal effects of treatment of ADHD with methylphenidate. J Am Acad Child Adolesc Psychiatry. 1997;36(6):754-763.

14. Barkley RA, Fischer M. Predicting impairment in major life activities and occupational functioning in hyperactive children as adults: selfreported executive function (EF) deficits versus EF tests. Developmental Neuropsychology. 2011;36(2):137-161.

15. Sartory G, Zorn C, Groetzinger G, Windgassen K. Computerized cognitive remediation improves verbal learning and processing speed in schizophrenia. Schizophr Res. 2005;75(2-3):219-223.

16. Bellucci DM, Glaberman K, Haslam N. Computer-assisted cognitive rehabilitation reduces negative symptoms in the severely mentally ill. Schizophr Res. 2003;59(2-3):225-232.

17. Bavelier D, Green CS, Pouget A, Schrater P. Brain plasticity through the life span: learning to learn and action video games. Annu Rev Neurosci. 2012;35:391-416.

18. Fine A, Goldman L. The effectiveness of computerized cognitive training and neurofeedback treatment in improving the functioning of ADHD children. 1993. Available from: http://www.braintrain.com/ the-effectiveness-of-computerized-cognitive-training-and-neurofeedbacktreatment-in-improving-the-functioning-of-adhd-children. Accessed June $15,2015$. 
19. Rabiner DL, Murray DW, Skinner AT, Malone PS. A randomized trial of two promising computer-based interventions for students with attention difficulties. J Abnorm Child Psychol. 2010;38(1):131-142.

20. Tinius T, Tinius KA. Changes after EEG biofeedback and cognitive retraining in adults with mild traumatic brain injury and attention deficit hyperactivity disorder. J Neurother. 2000;4(2):27-44.

21. Bangirana P, Giordani B, John CC, Page C, Opoka RO, Boivin MJ. Immediate neuropsychological and behavioral benefits of computerized cognitive rehabilitation in Ugandan pediatric cerebral malaria survivors. J Dev Behav Pediatr. 2009;30(4):310-318.

22. Hardy KK, Willard VW, Bonner MJ. Computerized cognitive training in survivors of childhood cancer: a pilot study. J Pediatr Oncol Nurs. 2011;28(1):27-33.

23. Farias AC, Cunha A, Benko CR, et al. Manganese in children with attention-deficit/hyperactivity disorder: relationship with methylphenidateexposure. J Child Adolesc Psychopharmacol. 2010;20(2): 113-118.

24. Weschsler D. Weschsler Intelligence Scale for Children. 3rd Ed. San Antonio, TX: The Psychological Corporation; 1991.

25. Shaffer D, Fisher P, Dulcan MK, et al. The NIMH Diagnostic Interview Schedule for Children Version 2.3 (DISC-2.3): description, acceptability, prevalence rates, and performance in the MECA study. $J$ Am Acad Child Adolesc Psychiatry. 1996;35(7):865-877.

26. American Psychiatric Association. Diagnostic and Statistical Manual of Mental Disorders. 4th ed, text revision. Washington, WC: American Psychiatric Association; 2000.

27. Shaffer D, Gould MS, Brasic J, et al. A children's global assessment scale (CGAS). Arch Gen Psychiatry. 1983;40(11):1228-1231.

28. do Nascimento E, de Figueiredo VL. WISC-III and WAIS-III: alterations in the current American original versions of the adaptations for use in Brazil. Psicol Reflex Crit. 2002;15(3):603-612.

29. Bates ME, Lemay EP Jr. The d 2 test of attention: construct validity and extensions in scoring techniques. J Int Neuropsychol Soc. 2004; 10(3):392-400.

30. Heaton HK. A Manual for the Wisconsin Card Sorting Test. Lutz (FL): Psychological Assessment Resources; 1981.

31. Osterrieth PA, Cambier A. Tentative d'enquête rigoureuse des enfants dessin. [Attempt at rigorous investigation of children's drawing]. Rev Neuropsychiatr Infant. 1969;17(6):393-409. French.

32. Watanabe K, Ogino T, Nakano K, et al. The Rey-Osterrieth Complex Figure as a measure of executive function in childhood. Brain Dev. 2005;27(8):564-569.

33. Holmes J, Gathercole SE, Dunning DL. Poor working memory: impact and interventions. Adv Child Dev Behav. 2010;39:1-43.

34. Dahlin E, Backman L, Neely AS, Nyberg L. Training of the executive component of working memory: subcortical areas mediate transfer effects. Restor Neurol Neurosci. 2009;27(5):405-419.

35. Breslau J, Miller E, Breslau N, Bohnert K, Lucia V, Schweitzer J. The impact of early behavior disturbances on academic achievement in high school. Pediatrics. 2009;123(6):1472-1476.

36. Chhabildas N, Pennington BF, Willcutt EG. A comparison of the neuropsychological profiles of the DSM-IV subtypes of ADHD. J Abnorm Child Psychol. 2001;29(6):529-540.
37. Farah MJ, Smith ME, Ilieva I, Hamilton RH. Cognitive enhancement. Wiley Interdiscip Rev Cogn Sci. 2014;5(1):95-103.

38. Wilens TE. Effects of methylphenidate on the catecholaminergic system in attention-deficit/hyperactivity disorder. J Clin Psychopharmacol. 2008;28(3 Suppl 2):S46-S53.

39. Molina BS, Hinshaw SP, Swanson JM, et al. The MTA at 8 years: prospective follow-up of children treated for combined-type ADHD in a multisite study. J Am Acad Child Adolesc Psychiatry. 2009;48(5): 484-500.

40. Rhodes SM, Coghill DR, Matthews K. Acute neuropsychological effects of methylphenidate in stimulant drug-naïve boys with ADHD II: broader executive and non-executive domains. J Child Psychol Psychiatry. 2006;47(11):1184-1194.

41. Blum NJ, Jawad AF, Clarke AT, Power TJ. Effect of osmotic-release oral system methylphenidate on different domains of attention and executive functioning in children with attention-deficit-hyperactivity disorder. Dev Med Child Neurol. 2011;53(9):843-849.

42. Zhang LI, Bao S, Merzenich MM. Persistent and specific influences of early acoustic environments on primary auditory cortex. Nat Neurosci. 2001;4(11):1123-1130.

43. Hasmann A, Trapp W, Schwerdtner J, Günther W, Zulley J, Dobmeier M. Leistungsfortschritte und Compliance schizophrener Patienten bei der Teilnahme am computergestutzten kognitiven Training mit der Software X-Cog. [Performance improvement and compliance of schizophrenic patients participating in the computerbased [sic] cognitive training with X-Cog]. Psychiatr Prax. 2004;31(suppl 1):S93-S95. German.

44. Plohmann AM, Kappos L, Ammann W, et al. Computer assisted retraining of attentional impairments in patients with multiple sclerosis. J Neurol Neurosurg Psychiatry. 1998;64(4):455-462.

45. Klingberg T. Training and plasticity of working memory. Trends Cogn Sci. 2010;14(7):317-324.

46. Rueda MR, Checa P, Combita LM. Enhanced efficiency of the executive attention network after training in preschool children: immediate changes and effects after two months. Dev Cogn Neurosci. 2012; 2(suppl 1):S192-S204.

47. Olesen PJ, Westerberg H, Klingberg T. Increased prefrontal and parietal activity after training of working memory. Nat Neurosci. 2004;7(1): 75-79.

48. Gray SA, Chaban P, Martinussen R, et al. Effects of a computerized working memory training program on working memory, attention, and academics in adolescents with severe LD and comorbid ADHD: a randomized controlled trial. J Child Psychol Psychiatry. 2012;53(12): $1277-1284$.

49. Lampit A, Hallock H, Valenzuela M. Computerized cognitive training in cognitively healthy older adults: a systematic review and meta-analysis of effect modifiers. PLoS Med. 2014;11(11):e1001756.

50. Hoekzema E, Carmona S, Ramos-Quiroga JA, et al. Training-induced neuroanatomical plasticity in ADHD: a tensor-based morphometric study. Hum Brain Mapp. 2011;32(10):1741-1749. 
Video abstract

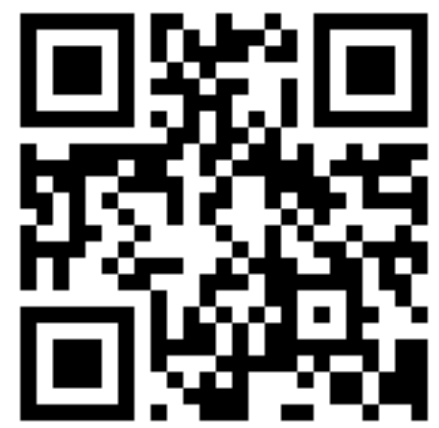

Point your SmartPhone at the code above. If you have a QR code reader the video abstract will appear. Or use: http://youtu.be/zKpTkgFS44A

\section{Publish your work in this journal}

Neuropsychiatric Disease and Treatment is an international, peerreviewed journal of clinical therapeutics and pharmacology focusing on concise rapid reporting of clinical or pre-clinical studies on a range of neuropsychiatric and neurological disorders. This journal is indexed on PubMed Central, the 'PsycINFO' database and CAS, and is the official journal of The International Neuropsychiatric Association (INA). The manuscript management system is completely online and includes a very quick and fair peer-review system, which is all easy to use. Visit http://www.dovepress.com/testimonials.php to read real quotes from published authors. 